\title{
MODELO ASSISTENCIAL EM SAÚDE MENTAL REPRESENTADO EM UM ESTRANHO NO NINHO, DE MILOS FORMAN, E A REFORMA PSIQUIÁTRICA NO BRASIL
}

\section{MENTAL HEALTH CARE MODEL DEPICTED IN ONE FLEW OVER THE CHUKOO'S NEST, BY MILOS FORMAN, AND PSYCHIATRIC REFORM IN BRAZIL}

\author{
Mirian Malacarne Ferrari'; Rodrigo Batista de Almeida ${ }^{1 *}$ \\ ' Curso de Farmácia, Instituto Federal do Paraná (IFPR) - Campus Palmas, Palmas (PR), Brasil \\ "Autor correspondente: Rodrigo Batista de Almeida, Instituto Federal do Paraná (IFPR) - Campus Palmas, \\ PRT 280, Trevo da Codapar, Av. Bento Munhoz da Rocha Neto, s/n, Palmas - PR, CEP 85.555-000 \\ Telefone: (046) 3262-1274 e-mail: rodrigo.almeida@ifpr.edu.br
}

\section{RESUMO}

Um dos filmes mais clássicos que retrata a "loucura" é Um estranho no ninho (One flew over the cuckoo's nest), de 1975, dirigido por Milos Forman. A história é centrada no personagem McMurphy, que finge ser "louco" para escapar do trabalho a que seria obrigado na prisão rural, onde cumpria pena. Levado para um hospital psiquiátrico, McMurphy tenta fugir quando descobre que a sua permanência nesse local será longa. Como castigo, McMurphy será lobotomizado. Este trabalho objetivou discutir aspectos relacionados à temática esquizofrenia e desinstitucionalização, a partir de elementos apresentados no filme. Apesar de o filme abordar o cenário norte-americano dos anos 1960, este trabalho utiliza o contexto da organização dos serviços em saúde mental apresentado no filme como o panorama que desencadeou o movimento da reforma psiquiátrica ao redor do mundo, inclusive no Brasil. A metodologia consistiu na análise do filme, a fim de identificar elementos relacionados à temática estudada, embasando uma discussão acerca da superação do modelo assistencial em saúde mental centrado no hospital psiquiátrico. O filme descreve a institucionalização e a aplicação indiscriminada, em circunstâncias punitivas, de eletroconvulsoterapia e lobotomia. Conclui-se que as situações retratadas no contexto do hospital psiquiátrico são, em grande medida, universais e refletem muitas das condições encontradas nas instituições manicomiais do Brasil, antes da reforma psiquiátrica implementada a partir de 2001. Essa reforma buscou superar o antigo modelo assistencial em saúde mental que privilegiava o internamento, o isolamento social e métodos repressores e punitivos, como o uso intenso de antipsicóticos e de eletroconvulsoterapia.

Palavras-chave: Cinema; Psicofarmacologia; Saúde Mental; Esquizofrenia; Desinstitucionalização.

\section{ABSTRACT}

One of the most classic films that depicts "madness" is One Flew over the Cuckoo's Nest, from 1975, directed by Milos Forman. The story centers on the character McMurphy, who pretends to be insane to avoid the job he would be forced to do in the rural prison, where he was serving sentence. Taken in a psychiatric hospital, McMurphy tries to escape when he discovers that he must stay there for a long time. As a punishment, McMurphy is going to be lobotomized. This work aimed to discuss the aspects related to schizophrenia and deinstitutionalization, based on elements presented in the One Flew over the Cuckoo's Nest. Although the film takes place at 1960s North American scenario, this work uses the context of the mental health system presented in the 
film as the panorama that triggered the psychiatric reform movement around the world, including in Brazil. The methodology consisted in the analysis of the film, to identify the elements related to the theme, supporting a discussion about overcoming the model centered in the psychiatric hospital. The film describes the institutionalization and application of therapeutic methods with a punitive purpose, such as electroconvulsive therapy and lobotomy. It is concluded that the situations depicted in the context of the movie's psychiatric hospital are, to a large extent, universal and reflect many of the conditions found in Brazilian psychiatric hospitals, before the psychiatric reform, implemented since 2001, which sought to overcome the old mental health system, which favored hospitalization, social isolation and repressive and punitive methods, such as the intense use of antipsychotics and electroconvulsive therapy.

Keywords: Motion Pictures; Psychopharmacology; Mental Health; Schizophrenia; Deinstitutionalization.

\section{INTRODUÇÃO}

"Loucura" é um termo pejorativo para se referir genericamente aos transtornos psicóticos. Esses transtornos estão relacionados à manifestação de psicose, caracterizada por delírios e alucinações. Delírio é uma crença absurda, inadequada e incompatível com a realidade, enquanto alucinação é uma experiência sensorial que ocorre na ausência de um estímulo físico (LANDEIRA-FERNANDEZ; CHENIAUX, 2010).

Entre os transtornos psicóticos, destaca-se a esquizofrenia. Os critérios diagnósticos para a esquizofrenia envolvem a presença, por pelo menos um mês, de no mínimo dois dos seguintes sintomas: delírios, alucinações, discurso desorganizado, comportamento grosseiramente desorganizado ou catatônico e sintomas negativos (AMERICAN PSYCHIATRIC ASSOCIATION, 2014).

As primeiras manifestações ocorrem no início da idade adulta, sendo raros os casos que antecedem a puberdade ou que surgem após os 50 anos. A prevalência de esquizofrenia é de $1 \%$ e os estudos epidemiológicos no Brasil não demonstraram diferenças em relação a outros países (MARI; LEITAO, 2000).

A base biológica para os sintomas positivos da esquizofrenia (delírio e alucinação) envolve alterações na via dopaminérgica mesolímbica, onde há exacerbação na neurotransmissão (STAHL, 2014).

Na Antiguidade, os "loucos" eram valorizados, pois eram vistos como dotados de atributos que lhes permitiam um contato direto com as divindades (BATISTA, 2018). Mas na maior parte da História, a "loucura" foi associada a elementos negativos, como castigo divino ou possessão demoníaca e isso justificava o tratamento desumano destinado aos indivíduos acometidos pela doença, os quais eram segregados do convívio social, sem o emprego de nenhuma medida terapêutica eficaz (SILVA, 1979).

O francês Pinel modificou, em parte, esse processo, sendo reconhecido como o responsável por ter libertado os doentes mentais das correntes de ferro que os prendiam nas instituições destinadas a manter essas pessoas isoladas, colocando a França na vanguarda da revolução psiquiátrica (SILVA, 1979). Mas, apesar de Pinel ter um papel importante no desenvolvimento e na melhoria do tratamento destinado aos doentes mentais, sua contribuição foi limitada e muita coisa ainda precisava ser modificada (MENDONÇA; ROSA, 2020). 
O modo de tratar os doentes mentais continuou, por muito tempo, baseado no encarceramento, sendo que as instituições psiquiátricas foram se tornando abrigos permanentes (OLIVEIRA; VALENÇA, 2020).

Além dos tratamentos inadequados, as pessoas que vivem com esquizofrenia sofrem pela incompreensão do seu sofrimento psíquico, havendo muito preconceito envolvendo essa doença, o que leva a estigma e a discriminação (LI et al., 2017). Os próprios familiares podem ser a origem do estigma e da discriminação (APARECIDO; SILVA, 2020).

Até mesmo as próprias pessoas com esquizofrenia podem internalizar o estigma a partir da consciência do estigma a elas atribuído, concordando e aplicando em si mesmos os estereótipos sobre sua condição. A internalização do estigma piora os sintomas, podendo levar ao isolamento social, baixa autoestima, culpa excessiva e autorreprovação (NASCIMENTO; LEÃO, 2019). O estigma (da sociedade, dos familiares e das próprias pessoas com esquizofrenia) impede esses indivíduos de buscar serviços terapêuticos adequados (BRUNOZI et al., 2019).

Em relação ao tratamento, há disponibilidade de abordagem farmacológica que, por vezes, é associada a medidas não-farmacológicas. O manejo farmacológico surgiu com a clorpromazina, que incialmente tinha sido concebida como um anti-histamínico (MAGALDI, 2020). Demonstrando eficácia no controle dos sintomas positivos da esquizofrenia, a clorpromazina inaugurou a chamada era moderna da Psicofarmacologia (GRAEFF, GUIMARÃES; ZUARDI, 1999).

Após a clorpromazina, outros antipsicóticos foram desenvolvidos. O haloperidol, lançado em 1958, teve grande destaque, sendo o "best seller" por muitas décadas. Em 1969, surgiu a flufenazina, numa formulação depot, o que revolucionou o tratamento, ao permitir um grande espaçamento entre as doses. Nos anos 1990, foram introduzidos os antipsicóticos atípicos, apresentando menor incidência de reações adversas (MONCRIEFF, 2013). Alterações no movimento (parkinsonismo farmacológico) e ganho de peso eram reações comuns decorrentes do uso dos antipsicóticos mais antigos (GOLDACRE, 2013).

O mecanismo de ação proposto para os antipsicóticos se baseia no antagonismo dos receptores dopaminérgicos e isso foi reconhecido ainda nos anos 1950, pela observação dos efeitos da clorpromazina e do haloperidol (BRUNTON; HILAL-DANDAN; KNOLLMANN, 2019).

No Brasil, no âmbito do sistema público de saúde, o acesso aos antipsicóticos de primeira geração (antipsicóticos convencionais) é viabilizado na Atenção Básica, enquanto os de segunda geração (antipsicóticos atípicos), pertencentes ao elenco dos medicamentos do Componente Especializado da Assistência Farmacêutica, são fornecidos mediante protocolos específicos (CUNHA, 2020).

Como a esquizofrenia tem forte apelo simbólico, até pelo estranhamento que causa, o cinema frequentemente a retrata. Um dos filmes mais clássicos que discutiram o tema foi Um estranho no ninho (One flew over the cuckoo's nest), de 1975, dirigido por Milos Forman.

O filme foi baseado no romance homônimo, de Ken Kesey, publicado em 1962. Na versão brasileira, ganhou o título Um estranho no ninho. O título original, que pode ser traduzido como "Um voo sobre o ninho do cuco", faz alusão ao cuco, o qual pode ser visto como um símbolo da loucura. Mas além do cuco, o título envolve o ninho do cuco, embora o cuco seja uma espécie que não faz ninho, colocando seus ovos no ninho de outra ave. Quando o cuco nasce, empurra os outros ovos para fora do ninho, sendo o único "filhote" a sobreviver. O personagem principal é o cuco da história, 
um sujeito que precisa adaptar-se a um meio ao qual fora submetido, mas que não condiz com a sua personalidade (OLIVEIRA, 2017).

O protagonista do filme é Randle Patrick McMurphy, um condenado em cumprimento de pena numa prisão rural que finge ser "louco" para escapar dos trabalhos a que estava sendo obrigado e poder cumprir o restante da pena numa instituição psiquiátrica. Mas essa estratégia não dará certo, pois McMurphy equivoca-se ao supor que cumpriria apenas o restante da sua pena no hospital.

Este trabalho objetivou discutir diferentes aspectos relacionados à temática esquizofrenia e desinstitucionalização, a partir de elementos apresentados no filme Um estranho no ninho. Apesar de o filme abordar o cenário americano dos anos 1960, este trabalho explora o contexto da organização dos serviços em saúde mental apresentado no filme como o panorama que desencadeou o movimento da reforma psiquiátrica ao redor do mundo, inclusive no Brasil.

\section{MATERIAL E MÉTODO}

A metodologia adotada consistiu na análise do filme Um estranho no ninho (One flew over the cuckoo's nest), de 1975, dirigido por Milos Forman, a fim de extrair os elementos relacionados à esquizofrenia, ao tratamento (farmacológico e não-farmacológico) desse transtorno mental e às características do modelo de assistência em saúde mental representado.

Apesar de o filme retratar uma realidade localizada em outra época (anos 1960) e em outro local (Estados Unidos da América), todos os elementos da narrativa fílmica reproduzem um padrão adotado em todo o mundo ocidental até o final do século XX e início do século XXI, quando ocorrem as reformas propostas pela luta antimanicomial.

Dessa forma, as dificuldades enfrentadas pelos pacientes (tanto pelo isolamento social quanto pelo agravamento dos sintomas psicóticos e piora da deterioração cognitiva), a dominação e o controle da instituição psiquiátrica sobre os internos e os métodos terapêuticos empregados rotineiramente como medidas punitivas, entre outros fatores, representam uma condição universal ligada às doenças mentais e ao modelo de institucionalização da "loucura" que se consolidou no século XX ao redor do mundo.

\section{RESULTADOS}

Ambientada numa instituição psiquiátrica, a história tem diversos personagens, tanto funcionários do hospital, como pacientes, além do protagonista, McMurphy. O diretor do hospital é o médico Dr. Spivey e a responsável pela ala aonde McMurphy é enviado é a enfermeira Ratched, que é assessorada pela auxiliar de Enfermagem Pilbow e por três homens (Washington, Miller e Warren), que parecem exercer uma função híbrida entre auxiliar de Enfermagem e segurança.

Há vários outros pacientes. Do núcleo mais próximo a McMurphy, estão Billy Bibbit (um rapaz jovem que apresenta gagueira e que aparentemente sofre pela personalidade dominadora de sua mãe), Harding (um homem com ciúme patológico e ideias delirantes sobre uma suposta traição cometida por sua esposa), Cheswick e Martini (estes últimos com outras manifestações de transtornos mentais). Há, também, Fredrickson, Sefelt, Taber e Scanlon, que geralmente estão presentes em muitas cenas, além de pacientes com graves problemas de comunicação, como o Chefe (um homem muito grande e forte, de origem indígena, que parece não ouvir nem falar), Bancini (com sinais evidentes de doença 
de Parkinson ou parkinsonismo, como tremor de mãos e dificuldade para controlar os movimentos) e Ellsworth (que permanece o tempo todo como se estivesse dançando).

Logo após chegar ao hospital, McMurphy vai aos poucos sendo integrado às atividades rotineiras. Tanto o filme quanto o livro retratam os anos 1960 e por isso reproduzem o que estava em voga em termos de tratamento para os transtornos mentais à época. Os medicamentos antipsicóticos, a eletroconvulsoterapia (prática vulgarmente chamada de "eletrochoque" e referida neste trabalho pela sigla ECT) e a lobotomia são algumas das opções terapêuticas representadas, embora aplicadas com finalidade diversa em muitas situações.

Outras atividades, como ginástica, terapia de grupo e atividades aquáticas em piscina, também são empregadas, embora sem a supervisão de profissionais da Psicologia, da Educação Física, da Fisioterapia ou da Terapia Ocupacional e isso é muito revelador da época retratada no filme, em que todos os procedimentos terapêuticos oferecidos nas instituições psiquiátricas eram realizados exclusivamente por profissionais da Medicina e da Enfermagem.

Os acontecimentos vão se alternando, sempre descrevendo a rotina do hospital psiquiátrico. Há momentos em que alguns pacientes jogam carta ou outros jogos, como Banco Imobiliário. Em alguns horários podem jogar basquete na área externa. Aos que têm autorização, é possível até sair do hospital para passeios organizados pela própria instituição. Mas, em todas essas situações, há um controle rígido por parte da enfermeira Ratched ou de alguns dos seus subordinados. Por outro lado, há os momentos dedicados a atividades terapêuticas, como a terapia de grupo ou sessão de ginástica, todas organizadas por Ratched.

As sessões de terapia de grupo se constituem, na realidade, num instrumento de controle e opressão. Numa das sessões, Ratched pede para Billy falar sobre a moça por quem estava apaixonado. Ratched induz Billy a falar sobre como abordou a moça e em qual circunstância a pediu em casamento, para, na sequência, confrontá-lo, dizendo que tudo era mentira e que ele não fez o que falava que havia feito. Ratched expõe Billy ainda mais ao revelar que esse fato estava ligado a uma tentativa de suicídio.

A atitude de Ratched não constrange apenas Billy. Cheswick, nitidamente incomodado, pergunta a Racthed "Se Billy não tem vontade de falar, por que o pressiona?". Ratched, sentindo-se desafiada, responde de forma ríspida que o objetivo da sessão é terapia, sugerindo que não é a percepção de um "igual", ou seja, de outro paciente com transtorno mental, que irá definir o protocolo desse procedimento terapêutico.

Como em toda instituição, há horários predeterminados para tudo, como, por exemplo, a "hora do remédio" e a "hora da recreação". No tempo livre, os pacientes ficam fumando ou jogando, sempre com uma música clássica ao fundo.

McMurphy vai mudando a percepção que tinha do hospital psiquiátrico. No momento em que chegou ao hospital e que foi libertado das algemas (numa das primeiras cenas do filme), solta um sorriso em estilo gargalhada, como se estivesse comemorando algo. McMurphy acreditava que a sua estratégia era perfeita, pois cumpriria o restante da pena sem ser obrigado a trabalhar.

Com o passar do tempo, percebe que a rotina do hospital é perturbadora. McMurphy, que no início imaginava que tudo poderia ser resolvido apenas questionando alguns procedimentos e solicitando algumas adaptações, passa a compreender que o poder da instituição sobre os pacientes é hegemônico. McMurphy não aceitava ter que ingerir comprimidos, ter que conviver com a música 
clássica constantemente sendo reproduzida numa intensidade de volume que impedia que a música passasse despercebida ou não poder assistir à final do campeonato pela televisão. Aos poucos, McMurphy se dá conta de que a institucionalização padroniza não só os procedimentos, mas também o comportamento dos pacientes.

Sem permissão para assistir à transmissão da final do campeonato, McMurphy narra um jogo hipotético, atraindo a atenção de vários dos pacientes. Esse fato irrita Ratched, provavelmente pela postura de resistência demonstrada por McMurphy e pela alteração na rotina dos internos, os quais, agora, atendem ao chamado de McMurphy e não mais às ordens da enfermeira.

McMurphy parece adotar um padrão de atitudes que representam uma estratégia de testar os limites da instituição. Profundo conhecedor das instituições prisionais, pelo seu histórico de inúmeros crimes, McMurphy ainda não conhecia a rigidez da estrutura que fundamenta e organiza as instituições psiquiátricas.

Num dos horários de recreação, embora sem permissão, McMurphy invade o ônibus que levaria os internos para um passeio e leva todos para uma pescaria. Antes de invadir um barco, passa pegar Candy, sua amiga que morava num trailer.

Já no barco, Billy elogia Candy, falando que seus cabelos e seus olhos eram bonitos. Apesar de a atitude de McMurphy ser indubitavelmente irresponsável (haja vista que ele se ausentou do hospital sem permissão, roubou um ônibus, invadiu um barco, levou vários pacientes para uma atividade sem autorização nem supervisão de nenhum funcionário da instituição etc.), McMurphy proporciona a Billy uma situação do cotidiano que envolve relacionamento interpessoal em que a aplicação de habilidades de comunicação é necessária. Mesmo às avessas, McMurphy traz a Billy uma prática efetivamente terapêutica, muito diferente das sessões de "terapia" em que Ratched se limita a constranger Billy, amplificando o seu sofrimento psíquico e, provavelmente, dificultando cada vez mais o controle dos sintomas do seu transtorno.

Como seria de se esperar, o comportamento de McMurphy é considerado grave o suficiente para motivar uma reunião com representantes de diferentes instituições, incluindo o Dr. Spivey, Ratched e pessoas externas ao hospital, a fim de decidir o que fazer com McMurphy. Ratched informa que deseja mantê-lo na sua enfermaria, o que ilustra muito bem o controle sobre os doentes mentais, tão frequente nas instituições psiquiátricas do século XX.

Em resposta ao espírito contestador de McMurphy, evidenciado em diferentes momentos ao longo da narrativa fílmica, a instituição aplica todo o seu arsenal de medidas punitivas, travestidas de procedimentos supostamente terapêuticos. Um exemplo é quando McMurphy se recusa a ingerir um comprimido, motivado pela negação em lhe fornecerem informações sobre a composição do medicamento. Isso leva Ratched a ameaçá-lo a usar outras vias de administração, sugerindo uma imobilização forçada para aplicação de injeções.

Numa outra situação, uma confusão iniciada numa das sessões de terapia leva McMurphy, além de Cheswick e do Chefe, à ECT. Cheswick foi o primeiro a ser levado e, enquanto aguardavam a sua vez, McMurphy oferece chicletes ao Chefe, o qual responde falando "Obrigado!". McMurphy espanta-se com o fato de o Chefe ouvir e falar normalmente e isso, de certa forma, estreita ainda mais os laços de amizade entre os dois. 
Ao retornar para a enfermaria, após a sessão de ECT, McMurphy demonstra aos colegas internos não ter sofrido, fazendo de sua experiência uma história até engraçada, brincando que agora estaria "energizado".

Todas as medidas impostas pelo hospital, geralmente partindo de Ratched, pareciam não abalar McMurphy, de modo que ele representava uma forma de resistência, sendo admirado pelos outros pacientes. Mas como a ameaça de injeções e a sessão de ECT não foram suficientes, a tentativa de fuga foi o motivo para a aplicação de uma técnica ainda mais agressiva, além de irreversível.

McMurphy começou a planejar uma fuga quando percebeu que não sairia tão facilmente do hospital como sairia de uma prisão. Transformado em ação concreta, o plano de fuga teve um desfecho desfavorável: a lobotomia.

Essa tentativa de fuga se insere num contexto mais complexo. Intencionando fugir, McMurphy chama duas amigas suas, Candy e Rose, para fazer uma espécie de festa de despedida. Tendo subornado Turkle, o guardião da noite, e com muita bebida, todos festejaram. McMurphy, que já tinha convidado o Chefe para fugir, acaba também convidando Billy, o qual revela não estar preparado. Percebendo seu encantamento por Candy, McMurphy pede para que ela se relacione sexualmente com Billy.

Todos acabam adormecendo e são surpreendidos pela equipe que chega de manhã para trabalhar (Ratched e seus assistentes Pilbow, Washington, Miller e Warren). Ratched vê Billy dormindo com Candy em um dos espaços do hospital e o submete a uma série de ameaças, todas convergindo para a ameaça maior: a necessidade de comunicação do ocorrido à sua mãe. Ratched sabia que a personalidade dominadora da mãe de Billy o perturbava.

Num descuido dos seguranças, McMurphy tenta abrir a tela de proteção da janela, mas é impedido. Tudo isso gera muita confusão, que só é interrompida pelo grito de Pilbow, que encontra Billy caído, já sem vida. O suicídio de Billy causa ainda mais confusão, levando McMurphy a tentar esganar Ratched. Essa atitude irá levar McMurphy a experimentar a lobotomia, a mais extrema das medidas de controle utilizadas nas instituições psiquiátricas.

Em uma das últimas cenas, o Chefe está deitado na cama, sem dormir, quando vê McMurphy chegando, amparado por dois auxiliares de Enfermagem. O Chefe vai até o leito de McMurphy e fala "Disseram que você fugiu. Sabia que não iria sem mim. Estava te esperando. Agora podemos ir, Mac. Me sinto grande como uma montanha".

Logo em seguida, o Chefe vê os dois cortes na cabeça de McMurphy, provenientes da cirurgia de lobotomia. O Chefe se desespera: "Ah, não! Não vou sem você. Não vou te deixar assim. Você vem comigo". McMurphy é morto pelo Chefe, asfixiado com um travesseiro. O Chefe, então, retira o equipamento de hidroterapia do chão, lança-o na janela, a fim de quebrá-la, e escapa do hospital.

Na última cena, a imagem fecha no Chefe, com a luminosidade característica do amanhecer. O Chefe está fugindo para uma área de mata, até desaparecer completamente. Resta a paisagem, que dialoga com a cena inicial do filme, que também retrata uma paisagem natural, com uma montanha com o cume nevado, uma área coberta por árvores e um lago. Na primeira cena, o horário parece ser o mesmo, pois o dia está amanhecendo. Com o afastamento da câmera, surge o contorno de uma estrada e, ao fundo, aparece um carro com os faróis ligados se aproximando. Era o carro levando McMurphy para ser internado no hospital psiquiátrico. 
Além da mesma ambientação (paisagem natural), a música reproduzida na última cena é a continuação da música que havia sido iniciada na primeira cena. Esses dois elementos (o som e a imagem), utilizados de forma associada, reforçam a sensação de narrativa circular, em que o final retoma o início.

A história, portanto, é cíclica, começando e terminando com a natureza. Começa com a entrada de McMurphy no sistema psiquiátrico e termina com a saída do Chefe do sistema psiquiátrico. Numa outra perspectiva, centrada no elemento natureza, explorado na primeira e na última cena, a história parece retomar o mito da origem do homem, apresentado no livro Gênesis, da Bíblia: "tu és pó e ao pó hás de voltar".

\section{DISCUSSÃO}

Um estranho no ninho é um clássico da contracultura dos anos 1960. A obra foi concebida num contexto histórico de ruptura, em que a "loucura", enquanto estatuto, estava sendo questionada. A "loucura", como metáfora da desordem, expressão cunhada pelo antropólogo francês Georges Balandier, representava tudo aquilo que deveria ser normalizado, garantindo a permanência do sistema social com indivíduos conformistas e obedientes. "O confinamento psiquiátrico, instrumentado pelo eletrochoque, pela lobotomia e pela então nascente psicofarmacologia, era o símbolo maior de uma forma de vida" (KESEY, 2009 grifo nosso).

A partir desses elementos, esta discussão foi organizada em tópicos, intitulados por algumas das falas dos dois personagens que compartilham o protagonismo na história, o interno McMurphy e a enfermeira Ratched. Em certa medida, é evidenciada uma possível aproximação entre a realidade apresentada no filme e o modelo de assistência em saúde mental adotado no Brasil, sobretudo o que vigorava antes da reforma psiquiátrica.

No entanto, é importante salientar que há algumas divergências entre a realidade representada no filme e a vivenciada no Brasil. Os internos dos antigos hospitais psiquiátricos brasileiros tinham, na sua maioria, características fortemente ligadas à exclusão social, como baixa escolaridade e predominância de raça/cor negra (BESSONI et al., 2019). A urbanização em massa, a miséria e as políticas excludentes para a população negra foram os fatores que fizeram que, no Brasil, o adoecimento mental fosse maior nessa população (MENEGAT; DUARTE; FERREIRA, 2020).

\section{"Nem consigo mais ouvir meus pensamentos" - condutas terapêuticas que amplificam a doença}

Ratched personifica a figura normatizadora da instituição. Envolvida em praticamente todas as atividades destinadas aos pacientes, Ratched sempre é acompanhada por auxiliares, reforçando o seu poder (SANTOS et al., 2020). Ratched é o estereótipo de muitos profissionais de saúde que eram responsáveis por alas de hospitais psiquiátricos e que comandavam com mãos de ferro o seu local de trabalho, sem tolerar qualquer indício de insubordinação por parte dos internos.

Muito comuns, em diversas instituições psiquiátricas, eram as práticas que se supunham terapêuticas, mas que na realidade eram sessões públicas de tortura. Nas sessões de "terapia", Ratched expunha os pacientes, humilhava-os e certamente colaborava para o agravamento dos seus transtornos.

É muito significativa a estratégia aplicada por Ratched para expor Billy, por exemplo. Ratched é exímia na técnica de fazer com que o paciente verbalize algumas situações que já são do conhecimento 
da enfermeira, para, na sequência, confrontá-lo e causar um conflito entre suas crenças, expectativas e realidades vivenciadas. No caso específico de Billy, Ratched sabe do impacto que a sua mãe, representando uma figura de dominação, tem para ele.

O suicídio, cometido por Billy, certamente foi impulsionado pelo pânico sistematicamente produzido por Ratched, haja vista a forma como a enfermeira conduziu o episódio em que Billy foi flagrado com sua amante. Portanto, o suicídio não só foi precipitado pela conduta de Ratched, como poderia ter sido previsto (e evitado) por essa mesma profissional. A identificação de casos mais vulneráveis ao suicídio é uma prática muito rotineira entre profissionais de saúde mental (MATA; DALTRO; PONDE, 2020). Desse modo, seria muito improvável que Ratched não considerasse um potencial suicídio.

\section{"Não gosto de tomar algo sem saber o que é" - confinamento, antipsicóticos, eletroconvulsoterapia e lobotomia: punição e controle com roupagem terapêutica}

McMurphy questionou a auxiliar de Enfermagem Pilbow sobre o que continha no medicamento entregue a ele. Diante da recusa em informá-lo e com a ameaça de que a administração de medicamentos poderia ocorrer à força, McMurphy aceita o comprimido. No entanto, cospe logo depois, numa atitude de resistência.

Essa sujeição imposta aos pacientes foi bem explorada no filme e era frequente nas diversas instituições psiquiátricas ao redor do mundo. A pessoa com transtornos mentais, uma vez institucionalizada, perdia a autonomia em decidir qual tratamento receberia ou em quais condições seria tratado. Além de não ser facultada a escolha do tratamento, a pessoa também não tinha o direito de receber informações sobre ele, como no caso de McMurphy, em que nem o medicamento empregado no seu caso lhe foi revelado.

Os antipsicóticos, introduzidos na terapêutica a partir dos anos 1950, integram o elenco de métodos terapêuticos vinculados ao isolamento nos hospitais psiquiátricos, instituições cuja implantação atingiu proporções gigantescas no século XX (CAMARGO, 2019). Ainda mais grave é o emprego dos métodos de ECT e lobotomia, quando desvirtuados do seu propósito terapêutico.

Austregésilo Carrano Bueno, autor do livro Canto dos Malditos, denunciou o tratamento recebido em hospitais psiquiátricos no Brasil. Austregésilo questiona o modelo assistencial em saúde mental: "Que tratamento? Engolir comprimidos e ficar preso, isolado, isso é tratamento? Crime não é apenas matar o nosso semelhante. É também deixá-lo inútil, matando sua iniciativa e vontade própria, transformando-o numa besta humana" (BUENO, 2004).

Assim como os medicamentos antipsicóticos, sobretudo os mais antigos, que têm o potencial de causar ou piorar os sintomas negativos da esquizofrenia, outros tratamentos promovem uma apatia, muito semelhante à descrita por Austregésilo Bueno. A lobotomia, prática desenvolvida pelo cirurgião português Antônio Egas Moniz, em 1935 (CAMARGO, 2015), causa um estado de avolia, que pode ser equivocadamente percebido como uma legítima resposta terapêutica a um tratamento voltado para o controle do comportamento em pacientes agressivos ou muito agitados.

Moniz desenvolveu a técnica após assistir a uma palestra em um congresso médico em Londres, na qual um neurologista de Yale apresentava os resultados de uma pesquisa em que se estudou as alterações observadas em pacientes que tinham o lobo frontal danificado. Os pacientes ficavam emocionalmente tranquilos, embora sua capacidade de pensar parecesse não se alterar (LIEBERMAN, 2016). A partir daí, a lobotomia ganhou adeptos no mundo todo, sobretudo na época pré-antipsicóticos. 
Menos agressiva e irreversível que a lobotomia, a ECT também figurou entre as práticas mais difundidas no tratamento de doentes mentais no século XX. A primeira sessão de ECT foi em 1938, chegando ao Brasil em julho de 1941. Com a introdução dos medicamentos antipsicóticos, a partir dos anos 1950, a ECT entra numa fase de leve declínio, embora ainda presente em muitas instituições, atendendo a propósitos diversos da sua finalidade precípua (ROSA; ROSA, 2015).

Legitimadas pelo alegado saber médico que amparava e subsidiava a aplicação terapêutica, a lobotomia e a ECT podem ser entendidas como dimensões biopolíticas da instituição psiquiátrica, a qual utiliza meios diversificados para operar o controle sobre os corpos dos doentes mentais (VOIGT, 2012).

No Brasil, uma das primeiras pessoas a questionar a validade de tratamentos como a ECT, a lobotomia e as internações sucessivas foi a médica psiquiatra Nise da Silveira, ainda nos anos 1940, antes da articulação do movimento antipsiquiátrico dos anos 1960/70 (MESSIAS, 2020).

A lobotomia foi paulatinamente caindo em desuso, em parte pelo uso amplamente difundido da ECT, em parte pela introdução dos medicamentos antipsicóticos, que causavam forte sedação, o que por si só já proporcionava um controle efetivo sobre o comportamento agitado dos pacientes (MIRANDA, 2014).

Em 2002, o Conselho Federal de Medicina estabeleceu regras específicas para o emprego da ECT, prevendo uso de anestesia e de relaxantes musculares, o que diferia substancialmente da técnica empregada anteriormente em muitos hospitais psiquiátricos pelo Brasil (ARBEX, 2013).

\section{"Por que ninguém falou que os médicos podem me manter aqui pelo tempo que quiserem?" - modelo de assistência em saúde mental ultrapassado}

Um dos símbolos máximos do modelo de assistência em saúde mental adotado no século XX, no contexto brasileiro, foi o Hospital-Colônia de Barbacena (Minas Gerais), inaugurado em 1903 e onde morreram mais de 60 mil pessoas (ALMEIDA; RHODEN, 2020).

Havia múltiplos interesses na manutenção desse hospital, conhecido como Colônia. Sendo o maior "hospício" do Brasil, entre 1969 e 1980, mais de 1800 cadáveres foram vendidos para faculdades de Medicina. Nesse hospital, aproximadamente 70\% dos pacientes não tinham diagnóstico de algum transtorno mental, mas isso não representava um obstáculo ao lucrativo negócio gerado pelos corpos (ARBEX, 2013).

Esses e outros casos semelhantes ao redor do mundo foram sendo divulgados a partir dos anos 1970, o que faria eclodir a luta antimanicomial, suplantando o modelo de assistência em saúde mental baseado no confinamento, controle e punição.

\section{"Precisa ter a maioria para mudar a política aqui" - reforma psiquiátrica e desinstitucionalização}

O italiano Basaglia foi o grande ícone da reforma psiquiátrica. Ele conheceu pessoalmente o Colônia e impulsionou o movimento da reforma psiquiátrica no Brasil no final dos anos 1970, curiosamente o período em que se ampliou a cobertura manicomial no país. Mas as principais discussões pela reestruturação da assistência psiquiátrica no Brasil ocorreram nos anos 1980 e 1990 (HIRDES, 2009; BRAGA; FARINHA, 2018).

Em 2001, foi aprovada a lei 10.216 (de 6 de abril de 2001), estabelecendo a descentralização do modelo assistencial em saúde mental, adaptando os serviços no paradigma psicossocial. A partir dessa 
regulamentação, a internação em saúde mental ficou restrita a situações excepcionais, quando os outros recursos extra-hospitalares fossem esgotados (BRASIL, 2001).

A lei 10.216/2001, portanto, é o marco legal da reforma psiquiátrica no Brasil, mas várias outras normas vieram na sequência para complementar a regulamentação da desinstitucionalização, como a lei 10.708/2003, que instituiu o Programa de Volta para Casa (PVC), destinado à reinserção social de pessoas que passaram por internação psiquiátrica de longa duração (GUERRERO, 2019).

As mudanças envolveram a criação de serviços substitutivos ao hospital psiquiátrico, como redes de atenção à saúde mental, Centros de Atenção Psicossocial (Caps), leitos psiquiátricos em hospitais gerais, oficinas terapêuticas e residências terapêuticas (HIRDES, 2009; BENETTI et al., 2020).

A reforma psiquiátrica no Brasil, que surgiu na proposta da desinstitucionalização, demonstrou ser possível uma sociedade sem manicômio, uma vez que a reforma se materializou em uma rede de serviços abertos, substituindo o antigo modelo, transformando vidas institucionalizadas em vidas que compartilham o comum (BRAGA, 2020).

Os contextos e cenários reais de vida de cada serviço substitutivo compõem a rede de atenção psicossocial em que se insere o cuidado e a construção da cidadania (BRAGA, 2019). Desse modo, é importante frisar que a desinstitucionalização não pode ser reduzida simplesmente à desospitalização, pois envolve uma reforma do modelo de atenção em saúde mental, visando a inclusão social e a promoção da cidadania (OLIVEIRA; PADILHA; OLIVEIRA, 2011).

No entanto, nem tudo que se refere à reforma psiquiátrica ocorreu sem conflito. Uma pesquisa que envolveu 12 Caps do estado de Santa Catarina evidenciou que, apesar de a maior parte dos profissionais que trabalham com saúde mental conhecer as propostas da desinstitucionalização previstas pela Política Nacional de Saúde Mental, com base na reforma psiquiátrica, esses profissionais identificam dificuldades para a efetiva implementação. Parte dos profissionais não acredita que a desinstitucionalização possa ser efetivada de forma integral, e, na percepção de outros, o sistema continua reproduzindo o modelo manicomial (MARTINHAGO; OLIVEIRA, 2015).

Isso é corroborado em outros trabalhos, em que há relatos de que, para algumas pessoas com esquizofrenia, a desinstitucionalização (nos manicômios) foi seguida por uma institucionalização (nos asilos), fortalecendo, portanto, a lógica manicomial (SIMONI; MOSCHEN, 2020).

Outro problema foi a expansão do uso de psicofármacos a partir da reforma psiquiátrica, o que sugere que o preço a ser pago pela desinstitucionalização é o aumento da medicalização do sofrimento psíquico (DIAS; MUHL, 2020).

São muitos desafios, portanto, para se efetivar a política de saúde mental, em benefício das pessoas com transtornos mentais. Além da pessoa em sofrimento psíquico, a família também precisa ser envolvida nas ações da rede de apoio psicossocial, pois não é raro haver intolerância de familiares para com os doentes mentais (ROCHA et al., 2020).

Em outra frente, é importante desenvolver estratégias de inclusão laboral para pessoas com esquizofrenia, que considerem as especificidades dos transtornos psicóticos e os fatores estressantes relacionados ao trabalho que podem se constituir em potenciais desencadeadores de sofrimento físico e emocional (MARTINI et al., 2019).

Por fim, é preciso, constantemente, recontextualizar a reforma psiquiátrica, pois novos cenários surgem, impondo novos desafios e exigindo medidas concretas para garantir a integração, à sociedade, das pessoas com transtornos mentais. Uma das situações atuais que demanda uma reorganização dos 
serviços em saúde mental é a pandemia de Covid-19, que criou condições desfavoráveis às pessoas com transtornos mentais, por aumentar (nessa população) o risco de contrair Covid-19, comprometer o fornecimento de medicamentos e desacelerar pesquisas clínicas em andamento. A pandemia de Covid-19, portanto, pode afetar desproporcionalmente as pessoas com esquizofrenia (KOZLOFF et al., 2020).

\section{CONCLUSÕES}

Conclui-se, a partir da análise do filme Um estranho no ninho, que as situações retratadas no contexto do hospital psiquiátrico são, em grande medida, universais e refletem muitas das condições encontradas nas instituições manicomiais do Brasil, antes da reforma psiquiátrica implementada a partir de 2001. Essas mesmas condições formaram o panorama que permitiu eclodir a luta antimanicomial, com os diversos desdobramentos nos diferentes países que passaram por esse processo.

No Brasil, mesmo com um atraso de muitos anos na implementação das reformas no sistema de saúde, houve um movimento na direção de uma superação do antigo modelo assistencial em saúde mental, que privilegiava o internamento, com isolamento social do paciente, aliado a métodos repressores e punitivos, como o uso intenso de antipsicóticos e ECT.

Após vinte anos do marco regulatório da reforma psiquiátrica no Brasil, muitos avanços podem ser percebidos, mas uma atenção constante é necessária para impedir que as situações descritas no filme Um estranho no ninho, verificadas em diversos locais ao redor do mundo, possam ser reproduzidas nos modelos de assistência em saúde mental.

\section{REFERÊNCIAS}

ALMEIDA, G. S.; RHODEN, C. Uma análise foucaultiana sobre o "holocausto brasileiro". Diaphonía, Toledo, v. 6, n. 1, p. 1-6, 2020.

AMERICAN PSYCHIATRIC ASSOCIATION. Manual diagnóstico e estatístico de transtornos mentais: DSM-5. (tradução Maria Inês Corrêa Nascimento et al.). 5. ed. Porto Alegre: Artmed, 2014.

APARECIDO, G. A.; SILVA, D. A. Pessoas com esquizofrenia: percepção acerca da discriminação e do estigma. Research, Society and Development, Vargem Grande Paulista, v. 9, n. 3, p. 1-20, 2020.

ARBEX, D. Holocausto brasileiro. São Paulo: Geração Editorial, 2013.

BATISTA, E. C. A Saúde mental e o cuidado à pessoa em sofrimento psíquico na história da loucura. Revista de Enfermagem e Saúde Coletiva, Rolim de Moura, v. 3, n. 2, p. 2-15, 2018.

BENETTI, A. S. et al. Existência e resistência dos corpos loucos: o corpo em processo e a reforma psiquiátrica brasileira. Saúde e Sociedade, São Paulo, v. 29, n. 4, p. 1-9, 2020.

BESSONI, E. et al. Narrativas e sentidos do Programa de Volta para Casa: voltamos, e daí? Saúde e Sociedade, São Paulo, v. 28, n. 3, p. 40-53, 2019.

BRAGA, C. P. A perspectiva da desinstitucionalização: chaves de leitura para compreensão de uma política nacional de saúde mental alinhada à reforma psiquiátrica. Saúde e Sociedade, São Paulo, v. 28, n. 4, p. 198-213, 2019. 
BRAGA, C. Argumentos para utopias da realidade e a experiência da reforma psiquiátrica brasileira. Saúde e Sociedade, São Paulo, v. 29, n. 3, e190054, 2020.

BRAGA, T. B. M.; FARINHA, M. G. Sistema Único de Saúde e a Reforma Psiquiátrica: desafios e perspectivas. Phenomenological Studies - Revista da Abordagem Gestáltica, Goiânia, v. 24, n. 3, p. 366-378, 2018.

BRASIL. Lei n ${ }^{\circ} 10.216$, de 6 de abril de 2001. Dispõe sobre a proteção e os direitos das pessoas portadoras de transtornos mentais e redireciona o modelo assistencial em saúde mental. Diário Oficial da União, Brasília, DF, 9 abr. 2001. p. 2.

BRUNOZI, N. A. et al. Grupo terapêutico em saúde mental: percepção de usuários na atenção básica. Revista Gaúcha de Enfermagem, Porto Alegre, v. 40, p. 1-9, 2019.

BRUNTON, L. L.; HILAL-DANDAN, R.; KNOLLMANN, B. C. (Org.). As bases farmacológicas da terapêutica de Goodman \& Gilman. (tradução Augusto Langeloh et al.). 13. ed. Porto Alegre: AMGH, 2019.

BUENO, A. C. Canto dos malditos. Rio de Janeiro: Rocco, 2004.

CAMARGO, C. H. F. (Org.). Neurologia e cinema. Ponta Grossa: UEPG, 2015.

CAMARGO, S. Esquizofrenia e experiência social: loucura, crítica e reconhecimento. ECOS Estudos Contemporâneos da Subjetividade, Campos dos Goytacazes, v. 9, n. 2, p. 296-307, 2019.

CUNHA, I. R. S. A esquizofrenia no componente especializado farmacêutico: aspectos clínicos e farmacoepidemiológicos. Research, Society and Development, Vargem Grande Paulista, v. 9, n. 8, p. 1-14, 2020.

DIAS, M. K.; MUHL, C. Agenciamentos da Psiquiatria no Brasil: Reforma Psiquiátrica e a epidemia de psicotrópicos. Argumentum, Vitória, v. 12, n. 2, p. 60-74, 2020.

GOLDACRE, B. Bad Pharma: how medicine is broken, and how we can fix it. London: Fourth Estate, 2013.

GRAEFF, F. G.; GUIMARÃES, F. S.; ZUARDI, A. W. Medicamentos antipsicóticos. In: GRAEFF, F. G.; GUIMARÃES, F. S. (Ed.). Fundamentos de Psicofarmacologia. São Paulo: Atheneu, 1999. p. 69-91, Cap. 5.

GUERRERO, A. V. P. et al. O Programa de Volta para Casa na vida cotidiana dos seus beneficiários. Saúde e Sociedade, São Paulo, v. 28, n. 3, p. 11-20, 2019.

HIRDES, A. A reforma psiquiátrica no Brasil: uma (re)visão. Ciência \& Saúde Coletiva, Rio de Janeiro, v. 14, n. 1, p. 297-305, 2009.

KESEY, K. Um estranho no ninho. (tradução Ana Lúcia Deiró). 11. ed. Rio de Janeiro: Record, 2009.

KOZLOFF, N. et al. The COVID-19 global pandemic: implications for people with schizophrenia and related disorders. Schizophrenia Bulletin, College Park, v. 46, n. 4, p. 752-757, 2020.

LANDEIRA-FERNANDEZ, J.; CHENIAUX, E. Cinema e loucura: conhecendo os transtornos mentais através dos filmes. Porto Alegre: Artmed: 2010.

$\mathrm{LI}$, J. et al. Stigma and discrimination experienced by people with schizophrenia living in the community in Guangzhou, China. Psychiatry Research, Cambridge, v. 255, p. 225-231, 2017. 
MODELO ASSISTENCIAL EM SAÚDE MENTAL REPRESENTADO EM UM ESTRANHO NO NINHO, DE MILOS FORMAN, E A REFORMA PSIQUIÁTRICA...

LIEBERMAN, J. A. Psiquiatria: uma história não contada. (tradução Fernando Santos). São Paulo: WMF Martins Fontes, 2016.

MAGALDI, F. Nas tramas da poção mágica: psicofármacos e criatividade em um hospital psiquiátrico do Rio de Janeiro. Revista de Antropologia, São Paulo, v. 63, n. 2, e146007, 2020.

MARI, J. J.; LEITAO, R, J. A epidemiologia da esquizofrenia. Revista Brasileira de Psiquiatria, São Paulo v. 22, supl.1, p. 15-17, 2000.

MARTINHAGO, F.; OLIVEIRA, W. F. (Des)institucionalização: a percepção dos profissionais dos Centros de Atenção Psicossocial de Santa Catarina, Brasil. Saúde e Sociedade, São Paulo, v. 24, n. 4, p. 1273-1284, 2015.

MARTINI, L. C. et al. Experiência laboral e inclusão social de indivíduos com esquizofrenia. Revista Brasileira de Saúde Ocupacional, São Paulo, v. 44, p. 1-10, 2019.

MATA, K. C. R.; DALTRO, M. R.; PONDE, M. P. Perfil epidemiológico de mortalidade por suicídio no Brasil entre 2006 e 2015. Revista Psicologia, Diversidade e Saúde, Salvador, v. 9, n. 1, p. 74-87, 2020.

MENDONÇA, J. R. S.; ROSA, M. As estabilizações na clínica das psicoses e das toxicomanias. Analytica, São João Del-Rei, v. 9, n. 16, p. 1-30, 2020.

MENEGAT, E. M.; DUARTE, M. J. O.; FERREIRA, V. F. Os novos manicômios a céu aberto: cidade, racismo e loucura. Em Pauta, Rio de Janeiro, v. 18, n. 45, p. 100-115, 2020.

MESSIAS, C. L. Arte e psicanálise no tratamento da psicose - proximidades e diferenças entre a proposta de Nise da Silveira e Henry Bauchau. Temáticas, Campinas, v. 28, n. 55, p. 195-226, 2020.

MIRANDA, C. A. C. Terapias biológicas e a prática da lobotomia nos hospitais psiquiátricos de Pernambuco na primeira metade do século XX. Saeculum - Revista de História, João Pessoa, n. 31 , p. 203-220, 2014.

MONCRIEFF, J. The bitterest pills: the troubling story of antipsychotic drugs. London: Palgrave Macmillan, 2013.

NASCIMENTO, L. A.; LEÃO, A. Estigma social e estigma internalizado: a voz das pessoas com transtorno mental e os enfrentamentos necessários. História, Ciências, Saúde - Manguinhos, Rio de Janeiro, v. 26, n. 1, p. 103-121, 2019.

OLIVEIRA, A. P. G. Razão ao avesso: uma análise da representação da loucura, dos loucos e dos manicômios em Cemitério dos Vivos e Diário do Hospício, de Lima Barreto, e Um Estranho no Ninho, de Ken Kesey. Pelotas, 2017. 77 p. Dissertação (Mestrado em Letras, área de concentração Literatura Comparada) - Universidade Federal de Pelotas.

OLIVEIRA, G. C.; VALENÇA, A. M. Institucionalização prolongada, transtornos mentais e violência: uma revisão científica sobre o tema. Saúde e Sociedade, São Paulo, v. 29, n. 4, p. 1-13, 2020.

OLIVEIRA, W. F.; PADILHA, C. S.; OLIVEIRA, C. M. Um breve histórico do movimento pela reforma psiquiátrica no Brasil contextualizando o conceito de desinstitucionalização. Saúde em Debate, Rio de Janeiro, v. 35, n. 91, p. 587-596, 2011.

ROCHA, S. A. et al. A origem da reforma psiquiátrica e uma amostra de cinema no Caps de Itumbiara - GO. Brazilian Journal of Development, Curitiba, v. 6, n. 10, p. 77001-7701 1, 2020.

ROSA, M. A.; ROSA, M. O. (Org.). Fundamentos da eletroconvulsoterapia. Porto Alegre: Artmed, 2015. 
SANTOS, A, F. et al. A imagem do ser enfermeira/enfermeiro em filmes de longa metragem à luz da história da enfermagem. Memorare, Tubarão, v. 7, n. 2, p. 249-265, 2020.

SILVA, V. A. A história da loucura: em busca da saúde mental. Rio de Janeiro: Ediouro, 1979.

SIMONI, A. C.; MOSCHEN, S. Histórias, visibilidades e princípios operadores da desinstitucionalização em saúde mental: narrativas do possível. Saúde e Sociedade, São Paulo, v. 29, n. 3, p. 1-13, 2020.

STAHL, S. M. Stahl Psicofarmacologia: bases neurocientíficas e aplicações práticas. 4. ed. Rio de Janeiro: Guanabara Koogan, 2014.

UM ESTRANHO no ninho. Direção: Milos Forman. Produção: Saul Zaentz e Michael Douglas. Intérpretes: Jack Nicholson; Louise Fletcher e outros. Roteiro: Lawrence Hauben e Bo Goldman. Música: Jack Nitzsche. Burbank: Warner Bros Pictures, 1975. 1 DVD (134 min), color.

VOIGT, L. "Um voo sobre o ninho dos cucos": uma análise da loucura considerando suas dimensões psicológica, social e política. Mosaico Social - Revista do Curso de Ciências Sociais da UFSC, Florianópolis, v. 6, n. 6, p. 255-270, 2012. 